\title{
Serum adiponectin concentrations in relation to maternal and perinatal characteristics in newborns
}

\author{
Christos Mantzoros $^{1}$, Eleni Petridou ${ }^{2,3}$, Delia-Marina Alexe ${ }^{2}$, Alkistis Skalkidou ${ }^{2}$, Nick Dessypris ${ }^{2}$, \\ Eugenia Papathoma $^{4}$, Heraklis Salvanos ${ }^{5}$, Greeshma Shetty ${ }^{1}$, Alina Gavrila ${ }^{1}$, Simos Kedikoglou ${ }^{2}$, \\ George Chrousos ${ }^{6,7}$ and Dimitrios Trichopoulos ${ }^{2,3}$ \\ ${ }^{1}$ Division of Endocrinology, Diabetes and Metabolism, Department of Internal Medicine, Beth Israel Deaconess Medical Center, Harvard Medical School, \\ Boston, Massachusetts, USA, ${ }^{2}$ Department of Hygiene and Epidemiology, Athens University Medical School, Athens, Greece, ${ }^{3}$ Department of \\ Epidemiology, Harvard School of Public Health, Boston, Massachusetts, USA, ${ }^{4}$ Department of Neonatology, 'Alexandra' Maternity Hospital, Athens,

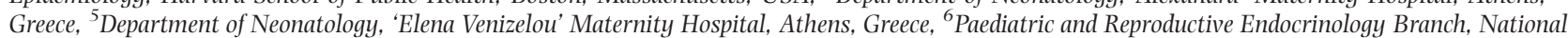 \\ Institute of Child Health and Human Development, NIH, Bethesda, Maryland, USA and ${ }^{7}$ First Department of Paediatrics, Ag. Sophia Children's Hospital, \\ Athens University Medical School, Athens, Greece
}

(Correspondence should be addressed to E Petridou, Department of Hygiene and Epidemiology, Athens University Medical School, 75 Mikras Asias Str, Goudi, Athens 115 27, Greece; Email: epetrid@med.uoa.gr)

\begin{abstract}
Objective: To assess serum adiponectin levels of neonates in relation to ponderal index and birth length with and without adjustment for potential confounding factors including maternal factors and perinatal characteristics.

Design: A cross-sectional study.

Methods: Three hundred and three newborns (Caucasian, singleton, full term, with a birth weight of $\geq 2500 \mathrm{~g}$, and apparently healthy) were included in the study. Blood samples were collected from the newborns no later than the fifth day of life for measurements of adiponectin and major IGF system components (IGF-I, IGF-II, IGF binding protein-3 (IGFBP-3)). The data were analyzed using simple and multiple regression analyses.

Results: Adiponectin is substantially higher in neonates than in adults, with no evidence of the gender dimorphism observed among adults. We found an inverse association between neonatal adiponectin levels and newborn ponderal index and a positive association with newborn length by univariate analysis. We also found a statistically significant inverse association of adiponectin with jaundice/bilirubin, and a marginally significant positive association of this hormone with IGFBP-3 but no significant association with any maternal factors. In multivariate analysis, the inverse association between serum adiponectin and ponderal index does not remain significant after adjustment for potential confounding factors. In contrast, neonatal adiponectin levels correlate inversely significantly and independently with liver maturity and IGF-II and tend to remain positively associated with IGFBP-3 and increased birth length.

Conclusions: An inverse association of adiponectin with ponderal index by univariate analysis is not independent from confounding factors. In contrast, the positive association between serum adiponectin and birth length may reflect either a direct effect of adiponectin or an adiponectin-mediated increase in the sensitivity of tissues to insulin and components of the IGF system, and needs to be explored further.
\end{abstract}

European Journal of Endocrinology 151 741-746

\section{Introduction}

Energy homeostasis during fetal development and the perinatal period is of considerable interest because of its implications for fetal growth and development. Perinatal development is influenced by multiple factors, including fetal, maternal and environmental conditions, which may interact with genotype to affect a range of physiological and pathological manifestations later in life such as the metabolic syndrome, cardiovascular disease and cancer $(1-4)$.

In adults, adiponectin, a $30 \mathrm{kDa}$ protein composed of 244 amino acids $(3,5)$, is exclusively secreted from adipose tissue and has been found to decrease with obesity (6), type 2 diabetes and insulin resistance (7), and to increase with weight reduction or administration of thiazolidinediones (8). Furthermore, recent observations indicate that adiponectin is inversely associated with markers of inflammation and endothelial dysfunction $(9,10)$ and is a significant inverse predictor of cardiovascular disease and cancer $(11-14)$. Thus, regulation of this adipokine in the perinatal period, when many metabolic, immune and hormonal pathways are being developed, is of great interest.

The purpose of this study was to assess serum adiponectin levels in relation to birth length and ponderal 
index in neonates. Although recently published studies have explored these associations mainly using cord blood, no previous study has evaluated serum adiponectin levels after multivariate adjustment for multiple potential confounders. We thus performed a cross-sectional study of 303 neonates to study these associations before and after adjustment for bilirubin levels and major components of the insulin-like growth factor (IGF) system as well as maternal factors, such as age and body mass index (BMI), and perinatal characteristics, including gender and gestational age. Specifically, we studied whether (i) neonatal adiponectin levels are associated with newborn length and ponderal index and (ii) whether these associations are independent of potential confounding by gender, gestational age and neonatal maturity or stress, maternal age and BMI, or potential underlying associations with other hormones including components of the IGF system.

\section{Materials and methods}

\section{Recruitment and clinical protocol}

During 1999, approximately 10000 newborns were delivered in the two departments of Obstetrics and Gynecology at the University of Athens teaching hospitals. These hospitals mostly admit lower income women from Greece, as well as migrant women from Albania, Poland, Bulgaria and other eastern European countries.

To be eligible for the study, neonates had to be Caucasian, singleton, full term (gestation period $\geq 37$ weeks, assessed by history and using the Ballard Maturational Assessment of Gestational Age (15) and ultrasound procedures) with a birth weight of $\geq 2500 \mathrm{~g}$, and had to be apparently healthy, i.e. without evidence of disease requiring intensive care or blood transfusions. Newborns were categorized into those who were jaundiced (bilirubin $>12 \mathrm{mg} / \mathrm{dl}$ ) and those who were non-jaundiced (bilirubin $<8 \mathrm{mg} / \mathrm{dl}$ ), considering blood bilirubin levels as an indicator of biological maturity $(16,17)$. To avoid misclassification, newborns with intermediate bilirubin levels were not included $(2,17,18)$. Women who developed gestational diabetes mellitus or had any chronic disease, such as malignancy, connective tissue disorder, diabetes mellitus, anemia, major neuro-psychiatric disorder, chronic renal failure, peptic ulcer disease, ulcerative colitis, asthma requiring treatment, or chronic infectious diseases including hepatitis $\mathrm{B}$ and $\mathrm{C}$, were excluded. Finally, in order to obtain a proper informed consent, the mother had to be able to communicate adequately in Greek or English. The University of Athens Medical School Ethics Committee approved the study protocol.

\section{Collection of samples and assays}

All eligible newborns were delivered while two of the authors (E Pap and H S) were the attendees on call; the mothers consented to participation in the study. A total of 68 newborns or their mothers did not satisfy the inclusion criteria and were excluded from the analysis. An additional 243 newborns with bilirubin levels between 8 and $12 \mathrm{mg} / \mathrm{dl}$ were excluded to avoid misclassification. Completed maternal questionnaires, as well as infant blood samples were obtained from a total of 323 newborns. Of these, another 20 newborns were excluded due to inadequate serum quantity, allowing 303 newborns to be included in the present analysis. All samples were collected no later than the fifth day of life (median day $=4$ ) in conjunction with a routine morning blood draw for bilirubin measurements and/or the nationally mandated screening for hypothyroidism, phenylketonouria and glucose-6-phosphate dehydrogenase deficiency.

Blood samples were obtained and sent for measurements of adiponectin under code at the Beth Israel Deaconess Medical Center in Boston, MA, USA. Adiponectin analysis was performed by radioimmunoassay (RIA) with a sensitivity of $2 \mathrm{ng} / \mathrm{ml}$ and an intra-assay coefficient of variation of $<10 \%$ as previously described (11-14). Major IGF system components (IGF-I, IGF-II, IGF binding protein-3 (IGFBP-3)) were also measured as previously reported $(17,18)$.

\section{Statistical analysis}

The data were analyzed using simple and multiple regression analyses. The SAS statistical program was used throughout (18). Values of adiponectin were approximately normally distributed, both in overall and in conditional analyses, so that no transformation was necessary to improve normality. Partial regression coefficients shown in the tables demonstrate percentage difference of serum adiponectin levels per specified differences in the predictor variable(s). A two-tailed $P$ value of 0.05 was considered statistically significant with a $95 \%$ confidence interval.

\section{Results}

Maternal and perinatal characteristics of the studied 303 newborns are shown in Table 1. As expected, the jaundiced neonates tended to be boys $(P=0.001$, data not shown) with a lower gestational age and a shorter birth length. The mean value of adiponectin was $32.2 \mu \mathrm{g} / \mathrm{ml}$ with a standard deviation of $10.3 \mu \mathrm{g} / \mathrm{ml}$, whereas the first, second and third quartiles were $25.3,32.2$ and $38.5 \mu \mathrm{g} / \mathrm{ml}$ respectively. No significant differences in adiponectin levels with regard to the day of blood draw were noticed.

In Table 2, serum adiponectin levels are compared between categories of maternal and perinatal characteristics, as well as levels of major components of the IGF system. There was no statistically significant evidence that maternal age, pre-pregnancy maternal 
Table 1 Distribution of 303 newborns by specified maternal and perinatal characteristics and by the presence of jaundice.

\begin{tabular}{lcccccc}
\hline & \multicolumn{2}{c}{ Jaundiced } & & \multicolumn{2}{c}{ Non-jaundiced } & \\
\cline { 2 - 3 } Variable & Mean & S.D. & & Mean & S.D. & P-value \\
\hline Maternal age (years) & 28.0 & 7.7 & & 27.9 & 8.7 & 0.98 \\
Pre-pregnancy maternal BMI $\left(\mathrm{kg} / \mathrm{m}^{2}\right)$ & 23.2 & 4.0 & & 22.4 & 3.8 & 0.12 \\
Gestational age (weeks) & 38.8 & 1.1 & 39.1 & 1.3 & 0.03 \\
Newborn length $(\mathrm{cm})$ & 51.0 & 2.4 & & 51.7 & 2.0 & 0.008 \\
Birth weight $(\mathrm{g})$ & 3307.6 & 419.1 & 3320.3 & 442.7 & 0.81 \\
Newborn ponderal index $\left(\mathrm{kg} / \mathrm{m}^{3}\right)$ & 25.0 & 3.0 & 24.1 & 3.3 & 0.015 \\
\hline
\end{tabular}

BMI, newborn gender or gestational age are associated with adiponectin levels. Moreover, there was no evidence for the existence of any non-linear associations. In contrast, longer newborns and non-jaundiced ones tended to have higher levels of adiponectin. Importantly, neonates with lower ponderal index had higher adiponectin levels $(P=0.01)$ by univariate analysis. IGF-I, IGFBP-3 and IGF-II were all strongly and significantly interrelated but adiponectin tended to be positively associated only with IGFBP-3 $(P=0.06)$. However, potential mutual confounding among maternal and perinatal characteristics may hinder inferences and this is particularly relevant for the strongly interrelated components of the IGF system.

Although adiponectin levels were lower in neonates above the median ponderal index, the latter was only weakly, inversely and marginally significantly $(P=0.05)$ associated with adiponectin levels by univariate analysis (data not shown). Even though this association remained significant after adjustment for gestational age $(P=0.03)$, it became non-significant after adjustment for maternal age and/or other potential confounders evaluated herein.

Table 2 Mean, standard error (S.E.) and Pearson correlation coefficients of serum adiponectin levels ( $\mu \mathrm{g} / \mathrm{ml}$ ) by specified maternal and perinatal characteristics as well as levels of selected compounds of the IGF system among 303 newborns.

\begin{tabular}{|c|c|c|c|c|c|}
\hline Variable & Mean & S.E. & $P$-value ${ }^{1}$ & Correlation coefficients & $P$-value ${ }^{2}$ \\
\hline Maternal age (years) & & & 0.09 & 0.007 & 0.90 \\
\hline$<30$ & 32.8 & 0.7 & & & \\
\hline $30+$ & 30.8 & 1.1 & & & \\
\hline Pre-pregnancy maternal BMI $\left(\mathrm{kg} / \mathrm{m}^{2}\right)$ & & & 0.18 & -0.002 & 0.98 \\
\hline$<25$ & 32.6 & 0.7 & & & \\
\hline $25+$ & 30.7 & 1.2 & & & \\
\hline Newborn gender & & & 0.69 & - & - \\
\hline Female & 31.9 & 0.9 & & & \\
\hline Male & 32.4 & 0.8 & & & \\
\hline Gestational age (weeks) & & & 0.74 & 0.057 & 0.32 \\
\hline $37-38$ & 31.9 & 0.9 & & & \\
\hline $39+$ & 32.3 & 0.7 & & & \\
\hline Newborn length (cm) & & & 0.02 & 0.16 & 0.005 \\
\hline$<51$ & 30.5 & 0.9 & & & \\
\hline $51+$ & 33.2 & 0.7 & & & \\
\hline Birth weight (g) & & & 0.97 & 0.073 & 0.20 \\
\hline$<3250$ & 32.1 & 0.9 & & & \\
\hline $3250+$ & 32.2 & 0.8 & & & \\
\hline Newborn ponderal index $\left(\mathrm{kg} / \mathrm{m}^{3}\right)$ & & & 0.01 & -0.093 & 0.10 \\
\hline$<24$ & 33.8 & 0.9 & & & \\
\hline $24+$ & 30.9 & 0.7 & & & \\
\hline Jaundice (bilirubin) (mg/dl) & & & $<0.001$ & - & - \\
\hline$\leq 8$ & 34.7 & 1.0 & & & \\
\hline$\geq 12$ & 30.5 & 0.7 & & & \\
\hline $\mid \mathrm{GF}-\mathrm{I}^{3}(\mathrm{ng} / \mathrm{ml})$ & & & 0.48 & 0.080 & 0.16 \\
\hline$\leq 24$ & 31.8 & 0.8 & & & \\
\hline $25+$ & 32.6 & 0.8 & & & \\
\hline$|G F-|^{3}(n g / m l)$ & & & 0.42 & -0.083 & 0.15 \\
\hline$\leq 469$ & 32.6 & 0.8 & & & \\
\hline $470+$ & 31.7 & 0.9 & & & \\
\hline IGFBP-3 ${ }^{3}(\mu \mathrm{g} / \mathrm{ml})$ & & & 0.06 & 0.103 & 0.076 \\
\hline$\leq 0.70$ & 31.2 & 0.8 & & & \\
\hline $0.71+$ & 33.3 & 0.9 & & & \\
\hline
\end{tabular}

${ }^{1} P$-value derived from $t$-test; ${ }^{2} P$-value for coefficients of correlation (Pearson); ${ }^{3}$ the cut-off points $24 \mathrm{ng} / \mathrm{ml}, 469 \mathrm{ng} / \mathrm{ml}$ and $0.70 \mu \mathrm{g} / \mathrm{ml}$ are the respective medians of IGF-I, IGF-II, IGFBP-3. 
In Table 3, the associations of adiponectin with maternal and perinatal characteristics as well as with major components of the IGF system are all mutually adjusted through multiple regression. Again, there was no evidence that maternal age, pre-pregnancy maternal BMI, newborn gender or gestational age, are associated with newborn serum adiponectin levels. Non-jaundiced newborns had significantly higher adiponectin levels and there was only a trend for a positive association between newborn length and adiponectin $(P=0.08)$. The strong and inverse association between adiponectin and IGF-II remains highly significant whereas the apparent positive association of adiponectin with IGFBP-3 failed to reach statistical significance $(P=0.06)$.

\section{Discussion}

Adiponectin, a recently discovered adipocyte-secreted hormone, is inversely associated with obesity, insulin resistance and type 2 diabetes, inflammatory markers, endothelial dysfunction $(3,10)$, and the development of cardiovascular disease and cancer in adults $(11-14)$. Modifiable predictors of adiponectin levels in neonates remain poorly studied.

Our data confirm recent findings that adiponectin levels in neonates are two to three times higher than levels in adults (20). Neonates have significantly less fat mass compared with children or adults $(\sim 50 \%)$, which is mainly subcutaneous fat and their adipocytes are either small, not containing fat, or are larger containing fat but are smaller in diameter than adult adipocytes (21-23). Moreover, adiponectin has also been found to be expressed in brown adipose tissue, which is atrophic in adults (24). The high adiponectin levels in neonates could also be due to the lack of an inhibitory effect of increased caloric intake and high fat diets on adiponectin production (25). All the above, and potentially other factors, may increase adiponectin levels which, in turn, may be responsible for the increased insulin sensitivity in neonates (26).

Similar to previous studies in neonates, we found no association between neonatal adiponectin levels and maternal factors such as maternal age and pre-pregnancy maternal BMI, suggesting that neonatal adiponectin levels are largely independent of maternal influences. Although adiponectin levels are higher in adult women than in men (27), we and others have found that this gender difference is not present at birth $(20,25,29-31)$. It remains unclear why the gender difference is absent at birth and perhaps the gender dimorphism of adiponectin levels develops later in life in response to sex steroids in the peripubertal period $(12,32,33)$. The role of gender with respect to adiponectin levels may prove to be of clinical importance, since it could also be directly related to gender differences in inflammatory responses and metabolic diseases later in life (28).

In contrast to adults, adiponectin levels in newborns did not correlate with body weight or ponderal index after potential confounding factors were adjusted for $(6,20)$. Previous studies have revealed conflicting results: some $(25,28,29,31)$ found a positive association between ponderal index and adiopnectin, whereas others $(20,30)$ showed no such relation. Hormonal factors, stress or gestational age may be responsible for the reported conflicting data $(20,25,27-31)$ but no previous study has performed multivariate adjustment to control for the potential effect of these potential confounders. Although gestational age had no significant effect, we found that adjustment for potential confounding factors, such as maternal age, renders the association between adiponectin and ponderal index to be non-significant. Thus it explains previously reported conflicting results indicating that these are probably due to uncontrolled confounding factors.

In this study, adiponectin was inversely associated with bilirubin/jaundice, a marker of stress and/or biological immaturity, which is consistent with previously published data that glucocorticoids inhibit adiponectin release in vitro (34), and that elevated cortisol levels in the stress state may lower adiponectin (35).

We have also assessed adiponectin in relation to neonatal length at birth. The primary established endocrine regulators of fetal growth include insulin and

Table 3 Multiple regression-derived estimates of adiponectin per indicated increment of predictor variables and corresponding 95\% confidence intervals (95\% Cls) among 303 studied newborns.

\begin{tabular}{|c|c|c|c|c|c|}
\hline \multirow{2}{*}{$\frac{\text { Variable }}{\text { Maternal age }}$} & \multirow{2}{*}{$\begin{array}{l}\text { Category or increment } \\
\quad \sim 5 \text { years more }\end{array}$} & \multirow{2}{*}{$\begin{array}{c}\text { Parameter estimate } \\
-0.50\end{array}$} & \multicolumn{2}{|c|}{$95 \%$ Cls } & \multirow{2}{*}{$\frac{P \text {-value }}{0.37}$} \\
\hline & & & -1.62 & 0.61 & \\
\hline Pre-pregnancy maternal BMI & $\sim 4 \mathrm{~kg} / \mathrm{m}^{2}$ & -0.55 & -2.07 & 0.97 & 0.48 \\
\hline Newborn gender & Female & Baseline & & & \\
\hline & Male & 1.19 & -1.22 & 3.60 & 0.33 \\
\hline Gestational age & $\sim 1$ week more & 0.05 & -1.02 & 1.12 & 0.93 \\
\hline Newborn ponderal index & $\sim 2 \mathrm{~kg} / \mathrm{m}^{3}$ & -0.05 & -1.11 & 1.01 & 0.93 \\
\hline Newborn length & $\sim 2 \mathrm{~cm}$ & 1.11 & -0.16 & 2.37 & 0.08 \\
\hline Jaundice (bilirubin) & $\begin{array}{l}\leq 8 \mathrm{mg} / \mathrm{dl} \\
\geq 12\end{array}$ & $\begin{array}{c}4.40 \\
\text { Baseline }\end{array}$ & 1.86 & 6.94 & 0.001 \\
\hline IGF-I & 1 standard deviation & 0.41 & -0.83 & 1.65 & 0.52 \\
\hline IGF-II & 1 standard deviation & -2.07 & -3.31 & -0.83 & 0.001 \\
\hline IGFBP-3 & 1 standard deviation & 1.18 & -0.07 & 2.42 & 0.06 \\
\hline
\end{tabular}


the IGF system (36). The IGF system plays a significant role in embryogenesis and fetal growth (37). Knockout animal models of IGF-I, IGF-II, insulin receptor and IGF-I receptor $(38,39)$ have significantly decreased birth weight and increased neonatal lethality. In contrast to IGF-II which is important in early gestation, IGF-I, which promotes somatic growth in late gestation, correlates well with birth weight (40-42). It would be important to document whether adiponectin, which has a known role not only in improving insulin and IGF sensitivity $(43,44)$, but also in promoting cell proliferation and inhibiting apoptosis $(45,46)$, could interact with or influence the production or tissue effects of these regulators of fetal growth. The significant association between adiponectin and newborn length by univariate analysis weakened and became of borderline significance after adjusting for the components of the IGF system, indicating that the association between adiponectin and length is probably mediated by alterations of the IGF system. This could potentially be explained by adiponectin acting as an insulin sensitizer $(43,44)$ and thus contributing to fetal growth (25). These novel findings need to be explored further by future in vitro and in vivo studies.

The strengths of this study include its relatively large size, which has provided the power needed to allow statistical documentation of important associations, the blinded measurements of hormone levels that minimizes misclassification, and the fact that this is the first study to perform multivariable adjustment for potential confounders such as gestational age, maternal factors and stress (28). While all previous studies have utilized cord blood, this research studied the above association using serum adiponectin levels of neonates. However, similar to all other previous studies, we did not measure fat mass directly, and did not assess centrality of fat distribution. Thus, it remains unknown whether a relationship of adiponectin with visceral fat exists at birth (20).

In summary, we confirmed previous findings of adiponectin being 2-3 times higher in neonates than in adults and we found no gender difference at this age. There was no significant association between neonatal adiponectin levels and maternal factors, while the inverse association with newborn ponderal index in univariate analysis did not persist after adjusting for potential confounding factors. We found statistically significant inverse associations of adiponectin with jaundice/bilirubin and IGF-II, and a marginally significant positive association of this hormone with birth length. The positive association between serum adiponectin and birth length may reflect either a direct effect of adiponectin or an adiponectin-mediated increase in the sensitivity of tissues to insulin and components of the IGF system, and needs to be studied further.

\section{Acknowledgements}

This study was financially supported by the University of Athens, the Greek Ministry of Health, the Department of Epidemiology Harvard School of Public Health, by NIDDK grant DK 58785, NIH grant 5T32DK07516-18, and an Eli Lilly and Co. fellowship award.

\section{References}

1 Langley-Evans SC, Gardner DS \& Welham SJ. Intrauterine programming of cardiovascular disease by maternal nutritional status. Nutrition $1998 \mathbf{1 4} 39-47$.

2 Skalkidou A, Petridou E, Papathoma E, Salvanos H, Chrousos G \& Trichopoulos D. Birth size and neonatal levels of major components of the IGF system: implications for later risk of cancer. Journal of Pediatric Endocrinology and Metabolism 200215 1479-1486.

3 Scherer PE, Williams S, Fogliano M, Baldini G \& Lodish HF. A novel serum protein similar to $\mathrm{C} 1 \mathrm{q}$, produced exclusively in adipocytes. Journal of Biological Chemistry 1995270 26746-26749.

4 Barker DJ. Fetal origins of cardiovascular disease. Annals of Medicine 199931 (Suppl 1) 3-6.

5 Maeda K, Okubo K, Shimomura I, Funahashi T, Matsuzawa Y \& Matsubara K. cDNA cloning and expression of a novel adipose specific collagen-like factor, apM1 (AdiPose Most abundant Gene transcript 1). Biochemical and Biophysical Research Communications $1996221286-289$.

$6 \mathrm{Hu}$ E, Liang P \& Spiegelman BM. AdipoQ is a novel adiposespecific gene dysregulated in obesity. Journal of Biological Chemistry 1996271 10697-10703.

7 Weyer C, Funahashi T, Tanaka S, Hotta K, Matsuzawa Y, Pratley RE \& Tataranni PA. Hypoadiponectinemia in obesity and type 2 diabetes: close association with insulin resistance and hyperinsulinemia. Journal of Clinical Endocrinology and Metabolism 200186 1930-1935.

8 Maeda N, Takahashi M, Funahashi T, Kihara S, Nishizawa H, Kishida K, Nagaretani H, Matsuda M, Komuro R, Ouchi N, Kuriyama H, Hotta K, Nakamura T, Shimomura I \& Matsuzawa Y. PPARgamma ligands increase expression and plasma concentrations of adiponectin, an adipose-derived protein. Diabetes $2001502094-2099$

9 Ouchi N, Kihara S, Funahashi T, Nakamura T, Nishida M, Kumada M, Okamoto Y, Ohashi K, Nagaretani H, Kishida K, Nishizawa H, Maeda N, Kobayashi H, Hiraoka H \& Matsuzawa Y. Reciprocal association of C-reactive protein with adiponectin in blood stream and adipose tissue. Circulation $2003 \mathbf{1 0 7}$ $671-674$.

10 Krakoff J, Funahashi T, Stehouwer CD, Schalkwijk CG, Tanaka S, Matsuzawa Y, Kobes S, Tataranni PA, Hanson RL, Knowler WC \& Lindsay RS. Inflammatory markers, adiponectin, and risk of type 2 diabetes in the Pima Indian. Diabetes Care $2003 \mathbf{2 6}$ $1745-1751$.

11 Mantzoros C, Petridou E, Dessypris N, Chavelas C, Dalamaga M, Alexe DM, Papadiamantis Y, Markopoulos C, Spanos E, Chrousos G \& Trichopoulos D. Adiponectin and breast cancer risk. Journal of Clinical Endocrinology and Metabolism 200489 1102-1107.

12 Gavrila A, Chan JL, Yiannakouris N, Kontogianni M, Miller LC, Orlova C \& Mantzoros CS. Serum adiponectin levels are inversely associated with overall and central fat distribution but are not directly regulated by acute fasting or leptin administration in humans: cross-sectional and interventional studies. Journal of Clinical Endocrinology and Metabolism $2003 \mathbf{8 8}$ 4823-4831.

13 Dal Maso L, Augustin LS, Karalis A, Talamini R, Franceschi S, Trichopoulos D, Mantzoros CS \& La Vecchia C. Circulating 
adiponectin and endometrial cancer risk. Journal of Clinical Endocrinology and Metabolism 200489 1160-1163.

14 Petridou E, Mantzoros C, Dessypris N, Koukoulomatis P, Addy C, Voulgaris Z, Chrousos G \& Trichopoulos D. Plasma adiponectin concentrations in relation to endometrial cancer: a case-control study in Greece. Journal of Clinical Endocrinology and Metabolism $200388993-997$.

15 Ballard JL, Khoury JC, Wedig K, Wang L, Eilers-Walsman BL \& Lipp R. New Ballard Score, expanded to include extremely premature infants. Journal of Pediatrics 1991119 417-423.

16 Ullrich D, Fevery J, Sieg A, Tischler T \& Bircher J. The influence of gestational age on bilirubin conjugation in newborns. European Journal of Clinical Investigation 199121 83-89.

17 Skalkidou A, Petridou E, Papathoma E, Salvanos H, Kedikoglou S, Chrousos G \& Trichopoulos D. Determinants and consequences of major insulin-like growth factor components among full-term healthy neonates. Cancer Epidemiology, Biomarkers and Prevention $200312860-865$.

18 Skalkidou A, Petridou E, Papathoma E, Salvanos H \& Trichopoulos D. Growth velocity during the first postnatal week of life is linked to a spurt of IGF-I effect. Paediatric and Perinatal Epidemiology $2003 \mathbf{1 7} 281-286$.

19 SAS system for windows, version 8. Cary, NC: SAS Institute Inc. 1999.

20 Lindsay RS, Walker JD, Havel PJ, Hamilton BA, Calder AA \& Johnstone FD. Adiponectin is present in cord blood but is unrelated to birth weight. Diabetes Care $2003262244-2249$.

21 Schmelzle HR \& Fusch C. Body fat in neonates and young infants: validation of skinfold thickness versus dual-energy X-ray absorptiometry. American Journal of Clinical Nutrition $2002 \mathbf{7 6}$ 1096-1100.

22 Boulton TJ, Dunlop M \& Court JM. The growth and development of fat cells in infancy. Pediatric Research $197812908-911$.

23 Soriguer Escofet FJ, Esteva de Antonio I, Tinahones FJ \& Pareja A. Adipose tissue fatty acids and size and number of fat cells from birth to 9 years of age - a cross-sectional study in 96 boys. Metabolism 199645 1395-1401.

24 Viengchareun S, Zennaro MC, Pascual-Le Tallec L \& Lombes M. Brown adipocytes are novel sites of expression and regulation of adiponectin and resistin. FEBS Letters 2002532 345-350.

25 Tsai PJ, Yu CH, Hsu SP, Lee YH, Chiou CH, Hsu YW, Ho SC \& $\mathrm{Chu} \mathrm{CH}$. Cord plasma concentrations of adiponectin and leptin in healthy term neonates: positive correlation with birthweight and neonatal adiposity. Clinical Endocrinology 200461 $88-93$.

26 Farrag HM, Nawrath LM, Healey JE, Dorcus EJ, Rapoza RE, Oh W \& Cowett RM. Persistent glucose production and greater peripheral sensitivity to insulin in the neonate vs the adult. American Journal of Physiology 1997272 E86-E93.

27 Comuzzie AG, Funahashi T, Sonnenberg G, Martin LJ, Jacob HJ, Black AE, Maas D, Takahashi M, Kihara S, Tanaka S, Matsuzawa Y, Blangero J, Cohen D \& Kissebah A. The genetic basis of plasma variation in adiponectin, a global endophenotype for obesity and the metabolic syndrome. Journal of Clinical Endocrinology and Metabolism 200186 4321-4325.

28 Pardo IM, Geloneze B, Tambascia MA \& Barros-Filho AA. Hyperadiponectinemia in newborns: relationship with leptin levels and birth weight. Obesity Research 200412 521-524.

29 Cianfarani S, Martinez C, Maiorana A, Scire G, Spadoni GL \& Boemi S. Adiponectin levels are reduced in children born small for gestational age and are inversely related to postnatal catchup growth. Journal of Clinical Endocrinology and Metabolism 2004 89 1346-1351.

30 Chan TF, Yuan SS, Chen HS, Guu CF, Wu LC, Yeh YT, Chung YF, Jong SB \& Su JH. Correlations between umbilical and maternal serum adiponectin levels and neonatal birthweights. Acta Obstetrica et Gynecologica Scandinavica 200483 165-169.

31 Sivan E, Mazaki-Tovi S, Pariente C, Efraty Y, Schiff E, Hemi R \& Kanety H. Adiponectin in human cord blood: relation to fetal birth weight and gender. Journal of Clinical Endocrinology and Metabolism $2003 \mathbf{8 8} 5656-5660$.

32 Lanfranco F, Zitzmann M, Simoni M \& Nieschlag E. Serum adiponectin levels in hypogonadal males: influence of testosterone replacement therapy. Clinical Endocrinology $200460500-507$.

33 Nishizawa H, Shimomura I, Kishida K, Maeda N, Kuriyama H, Nagaretani H, Matsuda M, Kondo H, Furuyama N, Kihara S, Nakamura T, Tochino Y, Funahashi T \& Matsuzawa Y. Androgens decrease plasma adiponectin, an insulin-sensitizing adipocytederived protein. Diabetes $2002512734-2741$.

34 Fasshauer M, Klein J, Neumann S, Eszlinger M \& Paschke R. Hormonal regulation of adiponectin gene expression in 3T3-L1 adipocytes. Biochemical and Biophysical Research Communications $20022901084-1089$.

35 Reincke M, Allolio B, Wurth G \& Winkelmann W. The hypothalamic-pituitary-adrenal axis in critical illness: response to dexamethasone and corticotropin-releasing hormone. Journal of Clinical Endocrinology and Metabolism 199377 151-156.

36 Milner RDG \& Gluckman PD. Regulation of intrauterine growth. In Pediatrics and Perinatology, The Scientific Basis, pp 284-289. Eds PD Gluckman \& MA Heymann. Arnold/Oxford University Press: London, 1996.

37 Valentinis B \& Baserga R. IGF-I receptor signalling in transformation and differentiation. Molecular Pathology 2001 54 133-137.

38 Baker J, Liu JP, Robertson EJ \& Efstratiadis A. Role of insulin-like growth factors in embryonic and postnatal growth. Cell 1993 $7573-82$.

39 Efstratiadis A. Genetics of mouse growth. International Journal of Developmental Biology 199842 955-976.

40 Giudice LC, de Zegher F, Gargosky SE, Dsupin BA, de las Fuentes L, Crystal RA, Hintz RL \& Rosenfeld RG. Insulin-like growth factors and their binding proteins in the term and preterm human fetus and neonate with normal and extremes of intrauterine growth. Journal of Clinical Endocrinology and Metabolism $1995 \mathbf{8 0}$ $1548-1555$.

41 DeChiara TM, Efstratiadis A \& Robertson EJ. A growthdeficiency phenotype in heterozygous mice carrying an insulin-like growth factor II gene disrupted by targeting. Nature $1990 \mathbf{3 4 5} 78-80$.

42 Wiznitzer A, Reece EA, Homko C, Furman B, Mazor M \& Levy J. Insulin-like growth factors, their binding proteins, and fetal macrosomia in offspring of nondiabetic pregnant women. American Journal of Perinatology 199815 23-28.

43 Kubota N, Terauchi Y, Yamauchi T, Kubota T, Moroi M, Matsui J, Eto K, Yamashita T, Kamon J, Satoh H, Yano W, Froguel P, Nagai R, Kimura S, Kadowaki T \& Noda T. Disruption of adiponectin causes insulin resistance and neointimal formation. Journal of Biological Chemistry 2002277 25863-25866.

44 Stefan N, Vozarova B, Funahashi T, Matsuzawa Y, Weyer C, Lindsay RS, Youngren JF, Havel PJ, Pratley RE, Bogardus C \& Tataranni PA. Plasma adiponectin concentration is associated with skeletal muscle insulin receptor tyrosine phosphorylation, and low plasma concentration precedes a decrease in wholebody insulin sensitivity in humans. Diabetes $2002 \quad \mathbf{5 1}$ $1884-1888$.

45 Brakenhielm E, Veitonmaki N, Cao R, Kihara S, Matsuzawa Y, Zhivotovsky B, Funahashi T \& Cao Y. Adiponectin-induced antiangiogenesis and antitumor activity involve caspase-mediated endothelial cell apoptosis. PNAS $20041012476-2481$.

46 Yokota T, Oritani K, Takahashi I, Ishikawa J, Matsuyama A, Ouchi N, Kihara S, Funahashi T, Tenner AJ, Tomiyama Y \& Matsuzawa Y. Adiponectin, a new member of the family of soluble defense collagens, negatively regulates the growth of myelomonocytic progenitors and the functions of macrophages. Blood 2000 $961723-1732$.

Received 29 July 2004

Accepted 28 September 2004 